\title{
Comparison between a Heat Pipe and a Thermosyphon Performance with Variable Evaporator Length
}

\author{
Dr. Hussain H. Ahmad \\ Anwar A. Yousif \\ University of Mosul - College of Engineering - Dept. of Mechanical Engineering
}

\begin{abstract}
Heat pipes and two phase thermosyphons are heat transfer devices whose operating principles are based on the evaporation/condensation of a working fluid using the capillary pumping forces (in the case of heat pipe) and gravity forces (in the case of two phase thermosyphons) to ensure the fluid circulation. The two systems were designed and constructed to investigate the performance and the affecting parameters, using ethanol as a working fluid. The affecting parameters which were studied are power input $(200 \leq \mathrm{Q} \leq 700) \mathrm{W}$, working fluid filling ratios $(35 \%$ and $85 \%)$ and aspect ratio, the ratio of evaporator length to inner diameter, (4.0, 7.8 and11.5) . The experimental results showed that the best performance of heat pipe obtained at aspect ratio $(7.8)$ and $(85 \%)$ filling ratio at $(500) \mathrm{W}$ where the maximum heat transfer coefficient was $(9950) \mathrm{W} / \mathrm{m}^{2}{ }^{\circ} \mathrm{C}$, while for the two phase thermosyphon the best performance was obtained at aspect ratio (4.0) for (35\%) filling ratio and power input (600) $\mathrm{W}$ with maximum heat transfer coefficient equals to $(4590) \mathrm{W} / \mathrm{m}^{2}{ }^{\circ} \mathrm{C}$. The overall comparison between the two systems showed that the performance of the heat pipe is better than that of the two phase thermosyphon. The experimental results of heat pipe was compared with theoretical and empirical correlations showing reasonable agreement especially with immura with percent $70 \%$.
\end{abstract}

KEY WORDS: heat pipe, two phase thermosyphon, aspect ratio, filling ratio

$$
\begin{aligned}
& \text { مقارنة بين أداء أنبوب حراري وسيفون حراري مع مبخر } \\
& \text { متغير الطول } \\
& \text { د. حسين حامد احمدة الموصل - كلية الهنسة ـ قسم الهنسة الميكانيكية أنوار احمد يوسف }
\end{aligned}
$$

الخلاصة

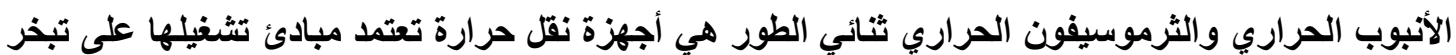

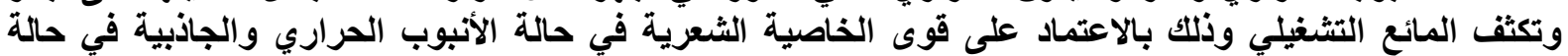

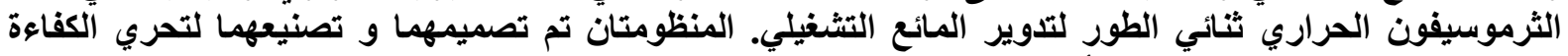

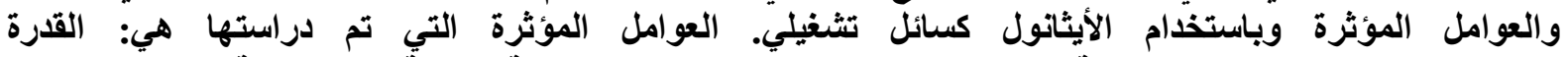

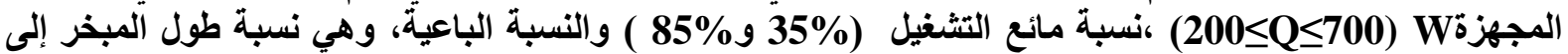

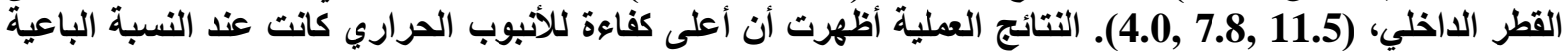

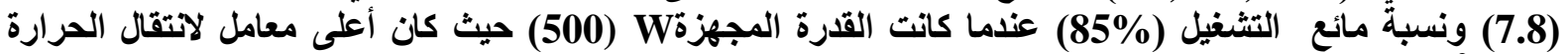
هو

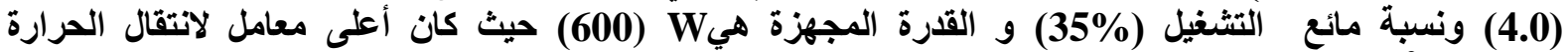
يساوي

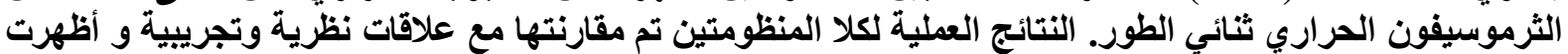

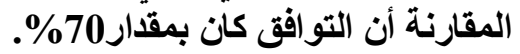




\section{Nomenclature}

\begin{tabular}{|c|c|c|c|c|}
\hline A & area & $\mathrm{m}^{2}$ & $\begin{array}{l}\text { Subs } \\
\text { cripts }\end{array}$ & \\
\hline AR & Aspect ratio (Le/di) & & $\mathrm{a}$ & adiabatic section, atmosphere \\
\hline Bo & bond number & & av & Average \\
\hline $\mathrm{C}_{\mathrm{p}}$ & specific heat & J/kg. ${ }^{\circ} \mathrm{C}$ & bo & Boiling \\
\hline $\mathrm{C}_{\mathrm{sf}}$ & constant & & $\mathrm{bl}$ & boiling limitation \\
\hline $\mathrm{d}$ & diameter of pipe & $\mathrm{m}$ & cap & Capillary \\
\hline FR & Filling ratio $(\mathrm{Vf} / \mathrm{Ve})$ & & $\begin{array}{c}\mathrm{CCF} \\
\mathrm{L}\end{array}$ & $\begin{array}{ll}\text { counter current flooding } \\
\text { limitation }\end{array}$ \\
\hline $\mathrm{g}$ & gravitational acceleration & $\mathrm{m} / \mathrm{s}^{2}$ & $\mathrm{e}$ & Evaporator section \\
\hline $\mathrm{h}$ & heat transfer coefficient & $\mathrm{W} / \mathrm{m}^{2} .{ }^{\circ} \mathrm{C}$ & eff & Effective \\
\hline $\mathrm{h}_{\mathrm{fg}}$ & latent heat of vaporization & $\mathrm{J} / \mathrm{kg}$ & en & entrainment \\
\hline$\hat{k u}$ & kutateladze number & & $\exp$ & experimental \\
\hline $\mathrm{K}$ & permeability & $\mathrm{m}^{2}$ & $\mathrm{f}$ & Fluid \\
\hline$k$ & thermal conductivity & $\mathrm{W} / \mathrm{m} .{ }^{\circ} \mathrm{C}$ & $\mathrm{i}$ & Inner \\
\hline $\mathrm{L}$ & pipe length & $\mathrm{m}$ & 1 & Liquid \\
\hline $\mathrm{m}$ & mass flow rate & $\mathrm{kg} / \mathrm{s}$ & $\max$ & Maximum \\
\hline $\mathrm{P}$ & pressure & $\mathrm{N} / \mathrm{m}^{2}$ & $\mathrm{n}$ & Nucleate \\
\hline $\operatorname{Pr}$ & prandtle number & & $\mathrm{rad}$ & Radial \\
\hline $\mathrm{Q}$ & heat transfer rate & $\mathrm{W}$ & sat & Saturation \\
\hline $\mathrm{Q}$ & heat flux & $\mathrm{W} / \mathrm{m}^{2}$ & SO & Sonic \\
\hline $\mathrm{R}$ & radius & $\mathrm{m}$ & $\mathrm{t}$ & Total \\
\hline $\mathrm{T}$ & temperature & ${ }^{\circ} \mathrm{C}$ & $\mathrm{v}$ & Vapor \\
\hline $\mathrm{V}$ & volume & $\mathrm{m}^{3}$ & $\mathrm{vp}$ & vapor-pressure \\
\hline$\mu$ & viscosity & $\mathrm{kg} / \mathrm{m} . \mathrm{s}$ & $\mathrm{W}$ & Wick \\
\hline$\rho$ & density & $\mathrm{kg} / \mathrm{m}^{3}$ & & \\
\hline$\sigma$ & surface tension & $\mathrm{N} / \mathrm{m}$ & & \\
\hline$\beta$ & angle of inclination & degree & & \\
\hline
\end{tabular}

\section{1: Introduction}

In the electronic industry, the component development is conducted by the increase in performance and the miniaturization of electronic systems, resulting in an increase of the heat dissipation. The thermal management of electronics becomes a major challenge. As conduction or air convection cooling systems are no more efficient to transfer such high heat fluxes so alternative cooling techniques (two-phase thermal control devices) have to be used such as heat pipe (HP) and two phase thermosyphon (TPTS). The major components of the heat pipe are a sealed container, working fluid, and a wick structure. The wick structure lines the pipe inside wall, which provides the structure to develop the capillary action causing the condensate to return back from the condenser to the evaporator as shown in Fig (1A). The two phase thermosyphon, Fig (1B), is nothing more than wickless heat pipe and the condensate returns from the condenser by gravitational force to the evaporator. Hence, there has been a considerable research focused on developing better models to predict the heat transfer achievement for a given temperature difference. Experimental and theoretical studies were carried out by Shiraishi, M. et al [2]the heat transfer characteristics of a two-phase closed thermosyphon were studied experimentally and a simple mathematical model was developed to predict the performance of such two phase thermosyphon. Lin, L. et al [8] developed high performance miniature heat pipes for the cooling of high heat flux electronics 
using new capillary structures made of folded copper sheet fin. An experimental investigation was performed to study the closed loop rectangular two phase thermosyphon besides numerical techniques by Basaran, T. et al [9]. Noie, S. H. [11] in his work studied the effect of three different parameters: input heat transfer rates $(100<\mathrm{Q}<900) \mathrm{W}$, the working fluid filling ratios $(30 \% \leq F R \leq 90 \%)$, and the aspect ratios (7.45,9.8 and 11.8). Kempers, R. et al [12] conducted an experimental study to determine the effect of the number of mesh layers and amount of working fluid on the heat transfer performance of copper-water heat pipe with screen mesh wicks. Carbajal ,G. et al [13] carried out both experimentally and computationally studies to investigate the temperature distribution a cross a flat heat pipe sandwich structure. Jiao, B. et al [15] carried out a comprehensive mathematical model to investigate the effect of filling ratio on the steady-state heat transfer performance of a vertical two-phase closed thermosyphon(TPCT). The overall thermal performance of closed twophase thermosyphon using nanofluids (stabilized suspensions of nanoparticales typically $(<100) \mathrm{nm}$ in conventional fluids) was investigated experimentally by Khandekar, S. et al [16]. From the above literature review, it is clear that no study was conducted to make a comparison between the performance of a heat pipe and a two phase thermosyphon. For this reason, the present study carried out a comparison experimentally taking into account the major affecting parameters such as heat flux, filling ratio and the aspect ratio. Also we could not find greatly research in which fluid (ethanol) is used in heat pipe and two phase thermosyphon. This is an important reason which encouraged us to use ethanol as a working fluid. The main objective of this study is to investigate experimentally the performance of a heat pipe and a two phase thermosyphon, then to make a comparison between them for the same working fluid, geometry and material. Many series of experimental tests were carried out at different parameters such as: filling ratios, aspect ratios at different power input.
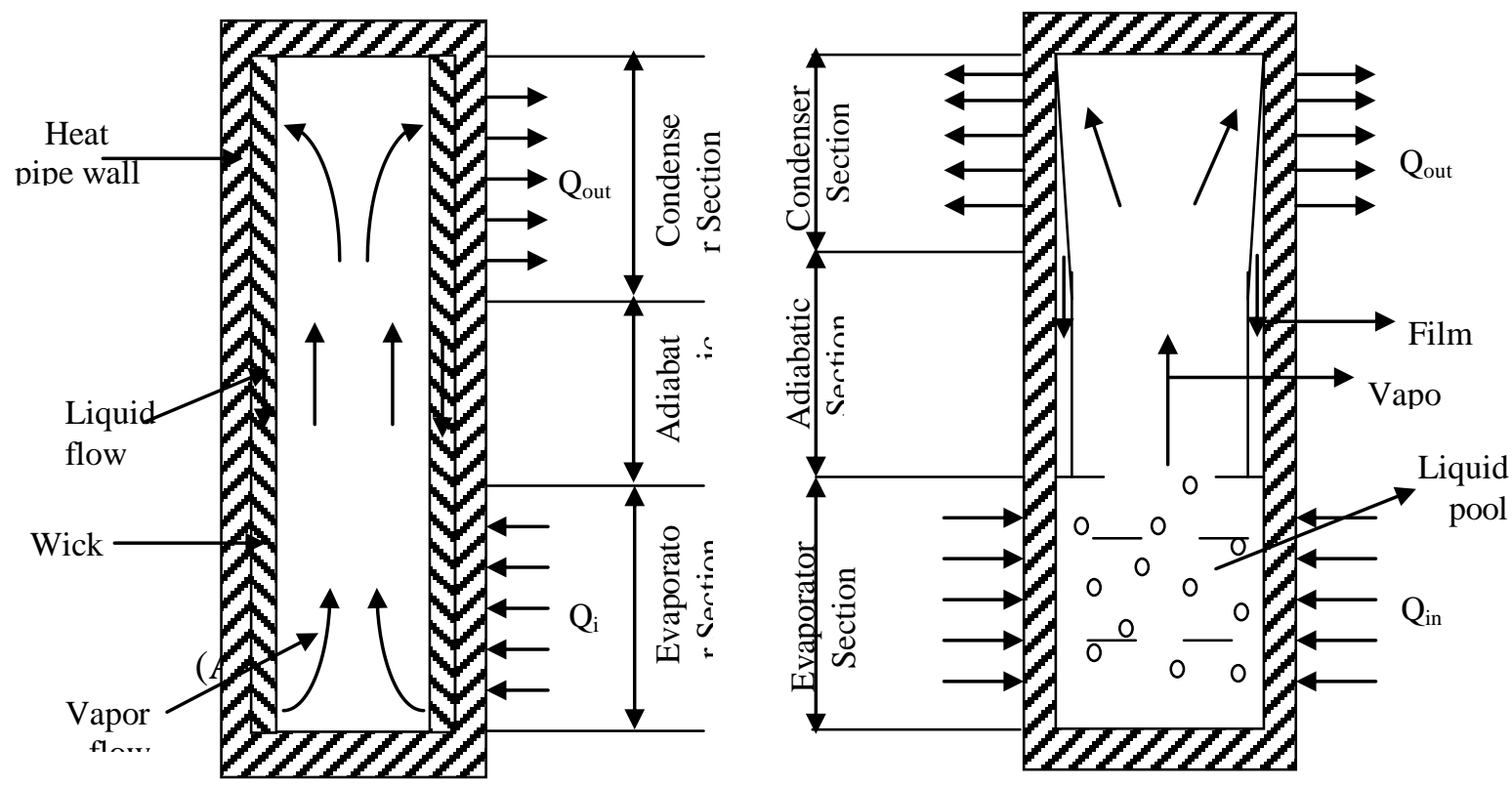

Figure(1):(A) Schematic diagram of a heat pipe and the associated heat flow mechanism(B)The two phase thermosyphon.

\section{2: Heat Transfer Limitations}

2-1: Heat Pipe Limitations: Heat pipe withstands more than one heat transfer limitation such as vapor-pressure, sonic, entrainment, capillary and boiling limitations. These limitations are depending on the working fluid, wick structure, dimensions of the heat pipe and the heat pipe operational temperature. The driving mechanism in the heat pipe is the heat 
input, Q, which is related to the mass flow rate of the working fluid and latent heat of vaporization $\left(h_{f g}\right)$.

$$
Q_{\text {max }}=m_{\text {max }} \times h_{f g}
$$

2-1-1: Viscous (Vapor-Pressure) Limit: This limitation takes place when the pressure drop in the vapor core reaches the same magnitude as the vapor pressure in the evaporator. Under these conditions, the pressure drop, due to flow through the vapor core, creates an extremely low vapor pressure in the condenser preventing vapor from flowing in the condenser [6]. A general expression for the vapor-pressure limitation is $[10,5]$ :

$$
Q_{v p \text { max }}=\frac{A_{v} r_{v}^{2} h_{f g} \rho_{v} P_{v}}{16 \mu_{v} L_{e f f}}
$$

2-1-2: Sonic Limit: The sonic limit is typically experienced in liquid metal heat pipes during start-up or low-temperature operation due to the associated very low vapor densities in this condition. An expression for this limit derived from one dimensional vapor flow theory $[10,5,14]$. with a final form:

$$
Q_{s o \text { max }}=0.474 A_{v} h_{f g}\left(\rho_{v} P_{v}\right)^{1 / 2}
$$

2-1-3: Entrainment Limit: The flow of the liquid and vapor in a heat pipe carries out in opposite direction. Thus the entrainment limitation develops when the vapour mass flow rate is large enough to shear droplets of liquid off the wick surface causing dry-out in the evaporator.

$$
Q_{e n \text { max }}=A_{v} h_{f g}\left[\frac{\sigma \rho_{v}}{2 r_{c a p}}\right]^{0.5}
$$

2-1-4: Capillary Limit: The capillary limitation in heat pipes occurs when the net capillary forces generated by the vapor-liquid interfaces in the evaporator and condenser are not large enough to overcome the frictional pressure losses due to fluid motion. The maximum heat transfer rate due to the capillary limitation can be expressed as $[6,5,14]$ :

$$
Q_{c a p \text { max }}=\left[\frac{\rho_{l} \sigma h_{f g}}{\mu_{l}}\right]\left[\frac{A_{w} \mathrm{~K}}{L_{e f f}}\right]\left[\frac{2}{r_{c a p}}+\frac{\rho_{l}}{\sigma} g L_{t} \cos \beta\right]
$$

2-1-5: Boiling Limit: This limitation occurs at higher heat fluxes. When this condition is reached nucleate boiling occurs in the wick structure and trapped the vapor in the wick, preventing return of condensate and resulting in evaporator dry out.

An expression for the boiling limitation is

$$
Q_{b o . \max }=\frac{2 \pi L_{e f f} T_{v} k_{e f f}}{h_{f g} \rho_{v} \ln \left(r_{i} / r_{v}\right)}\left[\frac{2 \sigma}{r_{n}}-\left(\Delta P_{c a p}\right)_{\max }\right]
$$


2-2: Two Phase Thermosyphon Limitations: Two-phase thermosyphon performance can be limited in different ways. The type of heat transport limitation depends on geometric dimensions (e.g. diameter, evaporator length ), working fluid fill charge and radial heat flux. In most cases, one of the three following performance limits can occur.

2-2-1: Dry-out Limit: The dry-out limit occurs at the bottom of the evaporator in the liquid falling film mode. This limit prevails for very small liquid fill charges and relatively small radial evaporator heat fluxes.

2-2-2: Boiling Limit: The boiling limitation occurs at the large liquid fill ratio and high radial heat fluxes. Vapor bubbles generated at high heat fluxes on the wall of evaporator and growth with increasing temperature, vapor bubbles coalesce at the near of the wall causing surface of vapor that prohibits the contact between the working fluid and the wall of pipe, due to the poor thermal conductivity of the vapor only part of the heat input to the wall is transferred to the liquid, resulting in rapid increase in evaporator wall temperature. For boiling

limitation, a correlation suggested by Immura et al[16,1] provides a good estimation of this limit:-

$$
Q_{\max }=A_{r a d} h_{f g} \rho_{v}^{0.5}\left[g \sigma\left(\rho_{l}-\rho_{v}\right)\right]^{1 / 4} \hat{K} u_{B L}
$$

Where

$$
\begin{aligned}
& \hat{K} u_{B L}=0.16\left[1-\exp \left\{\left(-d / L_{e}\right)\left(\rho_{l} / \rho_{v}\right)^{0.13}\right\}\right] \\
& A_{\text {rad }}=\pi d L_{e}
\end{aligned}
$$

2-2-3: Counter Current Flow (Flooding)Limit: The counter current flow limitation is one of the most important and common limitations found in closed two-phase thermosyphon with large liquid fill ratio, large axial heat fluxes and small radial heat fluxes. The vapor shear prevents the condensate from returning to the evaporator and leads to a flooding condition in the condenser section. The general correlation used in calculating this limit [7,4]is given by:-

$$
\begin{aligned}
& Q_{\max }=K u_{C C F L} h_{f g} A\left[g \sigma\left(\rho_{l}-\rho_{v}\right)\right]^{1 / 4}\left[\rho_{v}^{-1 / 4}+\rho_{l}^{-1 / 4}\right]^{-2} \\
& K u_{C C F L}=\left(\frac{\rho_{l}}{\rho_{v}}\right)^{0.14} \tanh ^{2} B o^{1 / 4} \\
& B o=d\left[g\left(\rho_{l}-\rho_{v}\right) / \sigma\right]^{1 / 2}
\end{aligned}
$$

All the above limitations was used to determine maximum heat transfer rate in heat pipes and two phase thermosyphon.

\section{3: Experimental Facility and Methodology}

The experimental work has been performed to investigate the effect of three parameters: input heat transfer rate, the working fluid filling ratio and aspect ratio. A series of experiments were carried out to find the influence of the above parameters on steady-state heat transfer characteristics in a vertical heat pipe and two phase thermosyphon. The two devices tested here were constructed using copper tube with an outside diameter of (35)mm and inside diameter of (32) mm with length of (1000) $\mathrm{mm}$ and the two ends of the pipe were 
closed with (3)mm thick copper end caps. The wick, for the heat pipe, was made from a woven stainless steel wire screen mesh with wire diameter of $(0.55) \mathrm{mm}$.

The evaporator section has a maximum length of (370)mm. It is heated electrically by three clamped heaters with length of (100)mm and (4)mm thickness each. The heaters are mounted between two layers of mica. They are

fixed tightly around the surface of the evaporator to ensure a good contact with its outer surface. The length of the evaporator section is varied by varying the length of the electrical resistance using one, two or three heaters in time. To prevent the heat losses, the entire length of the evaporator is insulated by asbestos having a thickness of (20)mm and wrapped with (50)mm thick fiber glass insulation. A further section is included to separate the evaporator and condenser which is known as the adiabatic section. The condenser has a length of(400)mm, cooled by water flowing through a (400)mm long concentric cylinder fabricated from a piece of galvanized plate with wall thickness (2) $\mathrm{mm}$ and inner diameter of(55)mm. The cooling water enters and exits the jacket through (16)mm diameter tube. The entire length of the pipe is wrapped with (50)mm thick fiber glass insulation to reduce heat losses. A pressure gauge, Bourdon type, was used to measure the vapor pressure inside the pipe. The pressure gauge is mounted on the top of the pipe

The wall temperature distribution along the pipe was measured using ten calibrated thermocouples (type K). The thermocouples are inserted in (1) $\mathrm{mm}$ grooves , machined in the outer surface of the wall, through a hollow tube with diameter of (5)mm soldered on the outside wall of the pipe as shown in Fig (2). An accurate wattmeter is connected in the heater circuit to record the exact power supplied . The temperature was read directly from a digital display.

Flow rate of the cooling water was determined by measuring the amount of the water over an interval of time. Water inlet and outlet temperatures were measured using two thermocouples. The experimental facility is shown in Fig (3) .

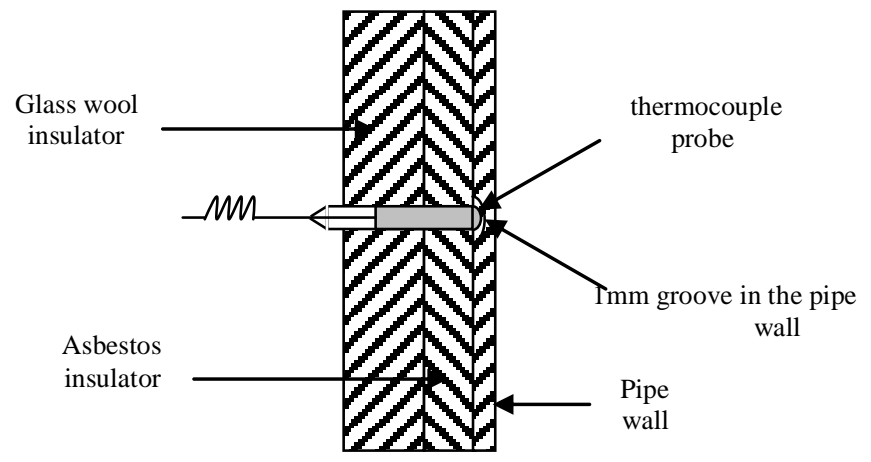

Fig(2):Detail of thermocouple fixing in the outside surface of the evaporator.

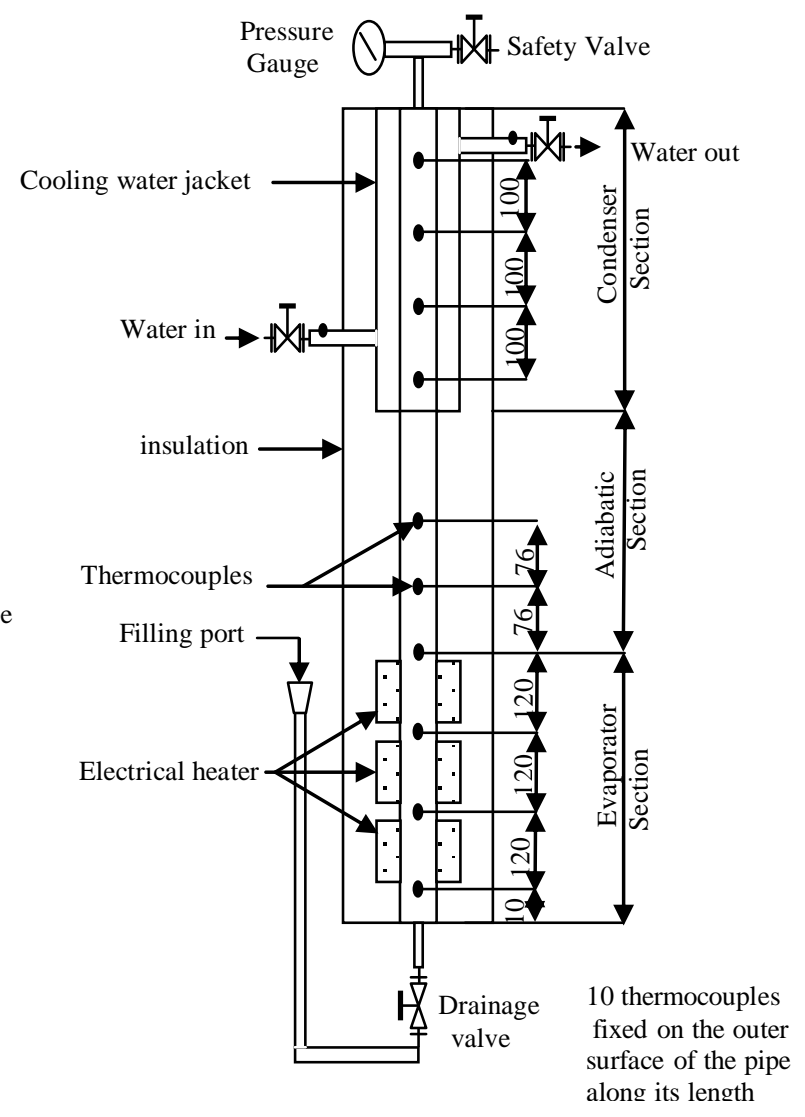

Figure(3) : Schematic diagram of the test rig. all dimensions in $\mathrm{mm}$ $(\mathrm{AR}=11.5)$ 


\section{4: The Experimental Tests}

\section{4-1: Factors Considered in the Experimental Work:}

1-Working fluid is Ethanol

2-Filling ratio of the working fluid :(35\% and $85 \%)$

( $\mathrm{FR}=$ Volume of working fluid / Volume of selected evaporator of a certain aspect ratio)

3-Power supply to evaporator:(200 to 700)Watts with interval of (100)W.

4-Aspect ratio:(4.0,7.8 and 11.5). Table (1)

Table (1): The relation between aspect ratio and filling ratio (FR).

\begin{tabular}{|c|c|c|c|}
\hline \multirow{2}{*}{ Aspect Ratio } & \multirow{2}{*}{$\begin{array}{c}\text { Evaporator } \\
\text { Volume }\left(\mathrm{cm}^{3}\right)\end{array}$} & \multicolumn{2}{|c|}{$\begin{array}{c}\text { Filling Charge } \\
\text { Volume }\left(\mathrm{cm}^{3}\right)\end{array}$} \\
\cline { 3 - 4 } & & FR=35\% & FR=85\% \\
\hline 4.0 & 102.9 & 36.0 & 87.5 \\
\hline 7.8 & 180.1 & 63.0 & 153.1 \\
\hline 11.5 & 297.6 & 104.1 & 252.9 \\
\hline
\end{tabular}

\section{4-2: Test Procedure:}

First, for a selected aspect ratio the heat pipe should be filled with a determined liquid charge up to $35 \%$ filling ratio. The end cap valves should be then closed. Then one or two or three heaters should be switched on (according to the selected aspect ratio). The water flow rate should be set at a certain value to cool the condenser. After a period of time, (30) minutes, the heat pipe should be purged to release air and gases and the purging valve is closed. The temperatures are recorded along the heat pipe for certain time intervals of (15)min. When the heat pipe reached steady state condition, all temperatures are recorded. Coolant flow rate is measured to calculate the heat transfer rate rejected by the condenser. The outside surface temperatures of the heat pipe and the ambient temperature are recorded to calculate the heat losses. The pressure was also recorded.

All the above procedures are going to be repeated for two phase thermosyphon.

After ending all the experiments for the selected aspect ratio and 35\% filling ratio (FR) then the apparatus should be set for the next aspect ratio by adjusting the liquid charge such that to be $35 \%$ of the new evaporator volume. Then the above procedure should be repeated for the next filling ratio.

\section{5: Results}

\section{5-1: Comparison Between Heat Pipe and Two Phase Thermosyphon Temperature Distribution with different Filling ratio and Aspect ratio:}

The variation of wall temperature along the two systems with respect to the filling ratio and aspect ratio are shown in Fig (4) and (5). It is clear that for filling ratio (35\%) the distribution of wall temperature along the evaporator in heat pipe is always higher than that in two phase thermosyphon for aspect ratio (4.0 and 11.5), while for aspect ratio (7.8), the temperature of the heat pipe is lower than that in two phase thermosyphon for lower power.

For filling ratio $(85 \%)$, the temperature distribution along the heat pipe and two phase thermosyphon at aspect ratio (4.0) is almost isothermal at lower powers. When aspect ratio equal to (7.8) the heat pipe shows isothermal distribution of temperature for all powers while the two phase thermosyphon shows an increasing in temperature at the middle of the evaporator this is a characteristic of the onset of evaporator dry-out due to capillary effect. For aspect ratio (11.5) the temperature for both systems is almost constant at lower power and begins to increase at higher power. The temperature of condenser for thermosyphon is higher than that of heat pipe for both filling ratios and for all aspect ratios. 

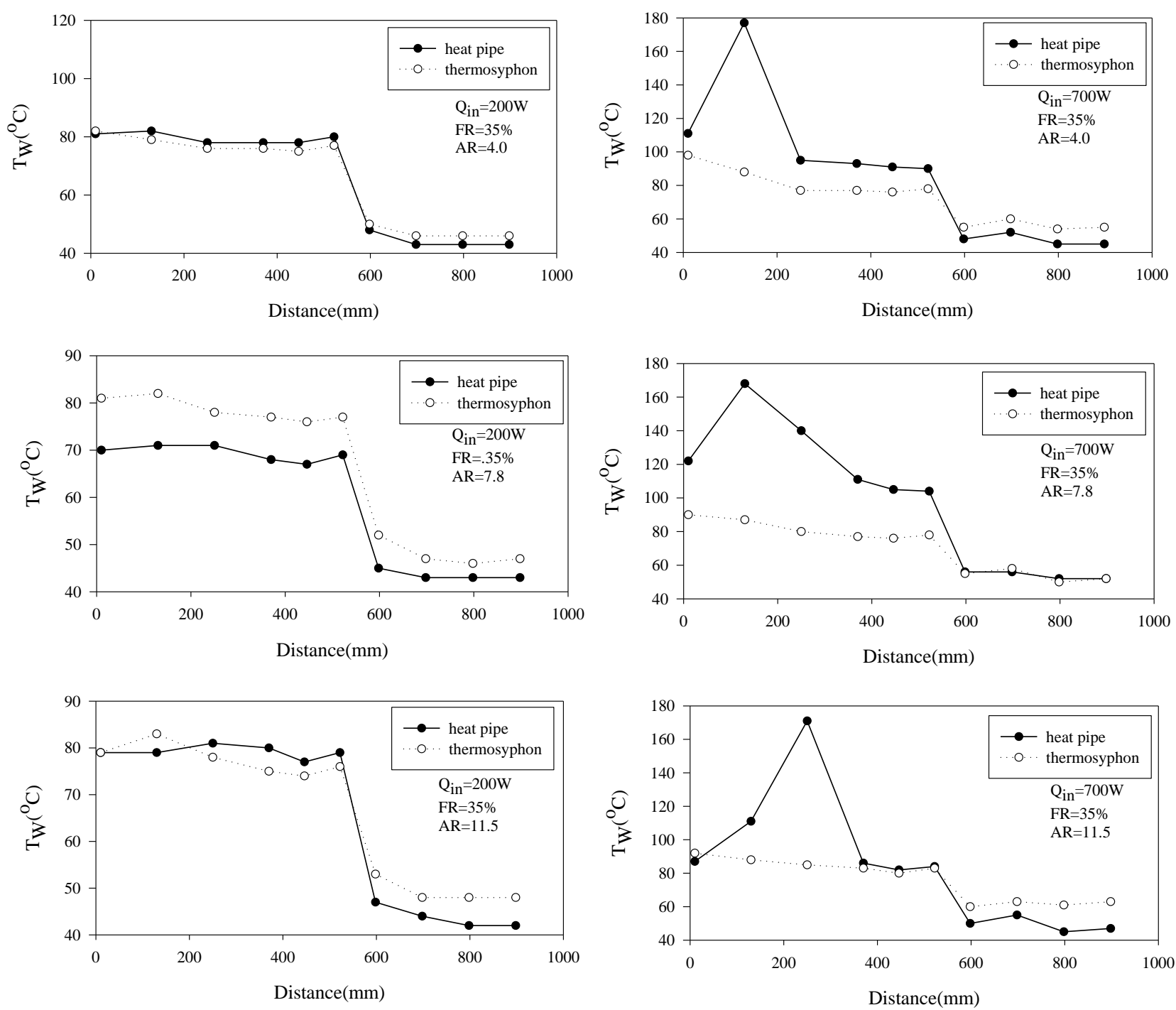

Figure(4):The surface temperature vs. distance for the two systems at different power input.

\section{5-2: Comparison of the Heat Transfer Coefficient Between The Heat Pipe and Two Phase Thermosyphon}

Figure (6) illustrates the effect of the aspect ratio on the heat transfer coefficient for a given filling ratio. In these cases, it is noticed that for filling ratio (35\%) at aspect ratio (4.0) the heat transfer coefficient decreases with the increasing power due to capillary effect, while for others (7.8 and 11.5) the heat transfer coefficient increases to a certain value then decreases. for two phase thermosyphon, it is clear that at aspect ratio (4.0) the heat transfer coefficient decreases with the increasing power to a certain value then increases to a maximum value. This reversed action is caused by dry-out, because the fill charge amount is low. While at aspect ratio is $(7.8,11.5)$ the heat transfer coefficient increases with the increasing power, but the increasing for aspect ratio (7.8) is higher than that of aspect ratio (11.5). For filling ratio (85\%) in heat pipe the heat transfer coefficient at aspect ratio (7.8) increases with the increasing power to reach a maximum value then decreases. While at aspect ratio (4.0) and (11.5) the heat transfer coefficient decreases with the increasing power due to dry-out condition. For two phase thermosyphon, at aspect ratios (4.0) and (11.5) the heat transfer coefficient increases with power increasing. While for aspect ratio (7.8), the heat 
transfer coefficient decreases at lower power then increases with the increasing power until (600) W then starts to decrease. This is due to the dry-out.

The maximum heat transfer coefficient is obtained in heat pipe at the filling ratio $(35 \%)$ and aspect ratio equal to(11.5), while at the filling ratio $(85 \%)$ the maximum heat transfer coefficient occurs when the aspect ratio is (7.8). For all giving filling ratios ,the minimum heat transfer coefficient occurs at the aspect ratio (4.0).
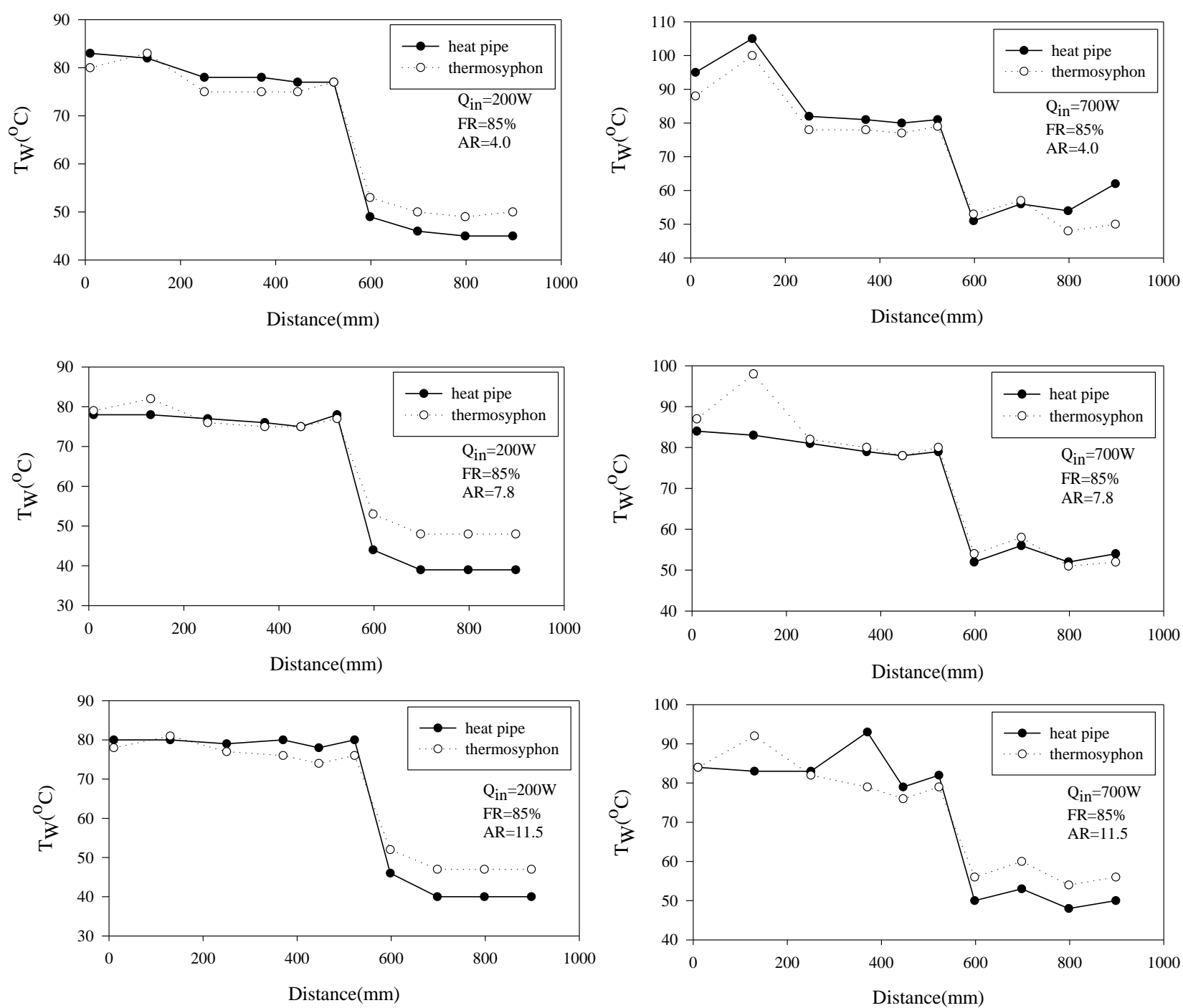

Figure (5): Surface temperature vs. distance for the two systems. 

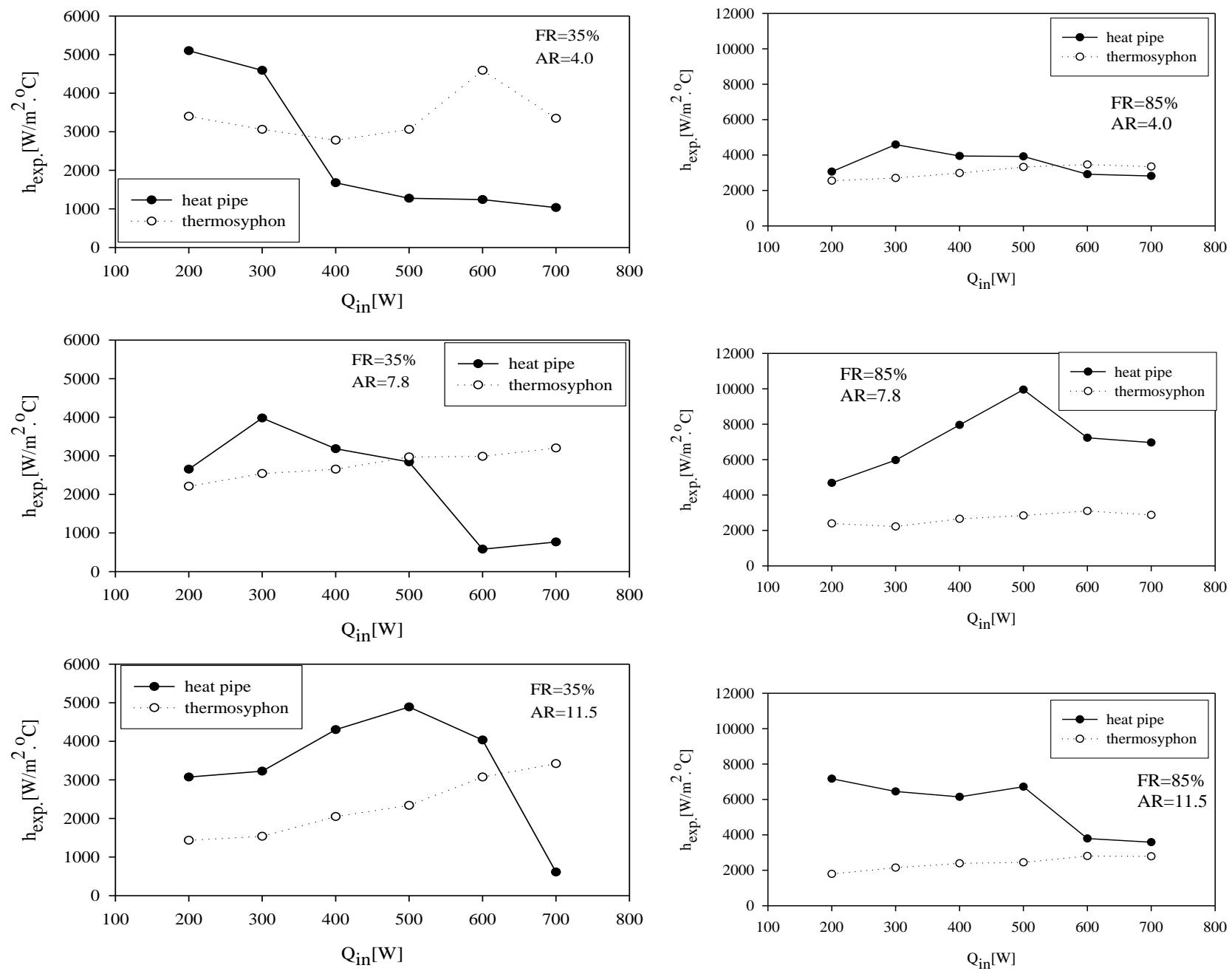

Figure(6):Comparison of heat transfer coefficient vs. power inpt

\section{5-3: Comparison of The Experimental Results With Theoretical and}

Empirical Correlations: The analysis of two-phase flow heat transfer in a two-phase closed two phase thermosyphon is very complicated. In this study, principally the analysis of the heat transfer characteristics to the fill charge ratio and aspect ratio with the power input ranging between $(200 \leq \mathrm{Q} \leq 700) \mathrm{W}$ was performed. From the measured data of wall temperature, the heat transfer coefficient in the evaporator can be evaluated using the following equation:-

$$
h_{\text {exp. }}=\frac{Q_{\text {in }}}{\pi d_{i} L_{e}\left(T_{e, a v .}-T_{v, a v .}\right)}
$$

The heat transfer mechanisms at the evaporator occur in various patterns; natural convection, evaporation, nucleate boiling and the combination of them. For a small fill charge ratio, convective boiling and evaporation at the condensate film returning to the evaporator is a dominating heat transfer mechanism. However as the fill charge ratio increases the nucleate boiling dominates the heat transfer mechanism in the evaporator.

In a previous study[5], it was found that nucleate boiling is the dominant mechanism in the evaporator, when the filling ratio is higher than $(30 \%)$. Therefore, the 
following two correlations based on nucleate boiling were chosen to compare with experimental data. These are Roshenows correlation[1]

$h_{\text {Roshenow }}=\left(\frac{q}{h_{f g}}\right)^{0.67}\left[\mu_{l} / \sqrt{\frac{\sigma}{g\left(\rho_{l}-\rho_{v}\right)}}\right]^{0.33} \frac{c_{p_{l}}}{c_{s f}} \frac{1}{p r_{l}^{1.7}}$

and Immura's correlation[3]

$$
h_{\operatorname{Im} \text { mura }}=0.32\left(\frac{\rho_{l}^{0.65} k_{l}^{0.3} c p_{l}^{0.7} g^{0.2} q^{0.4}}{\rho_{v}^{0.25} h_{f g}^{0.4} \mu_{l}^{0.1}}\right)\left(\frac{P_{s a t}}{P a}\right)^{0.3}
$$

Fig (7) shows that the heat transfer coefficient of the experimental results is higher than that obtained by the two other correlations specially when the aspect ratio is (11.5) and the filling ratio is $(35 \%)$. This truth also can be seen when the aspect ratio is (11.5) and the filling ratio is $(85 \%)$. Generally the curves are in the same profile.

\section{6: Conclusions}

1. In most cases, the outside surface temperatures of evaporator section in two phase thermosyphon are lower when filling ratio (35\%) for all aspect ratios, whereas in heat pipe the lower temperature of evaporator section was obtained at filling ratio $(85 \%)$.

2. The higher temperature distribution was obtained in heat pipe and two phase thermosyphon at aspect ratio (4.0) for all filling ratios.

3. In the heat pipe the maximum heat transfer coefficient obtained at filling ratio $(85 \%)$ and aspect ratio (7.8) which equal to $(9950) \mathrm{W} / \mathrm{m}^{2} .{ }^{\circ} \mathrm{C}$, while in two phase thermosyphon the maximum heat transfer coefficient with filling ratio $(35 \%)$ and aspect ratio (4.0) is (4590)W/m $\mathrm{m}^{2}{ }^{\circ} \mathrm{C}$.

4. The wall temperature distribution in heat pipe shows more intensity than two phase thermosyphon.

5. The experimental data generally
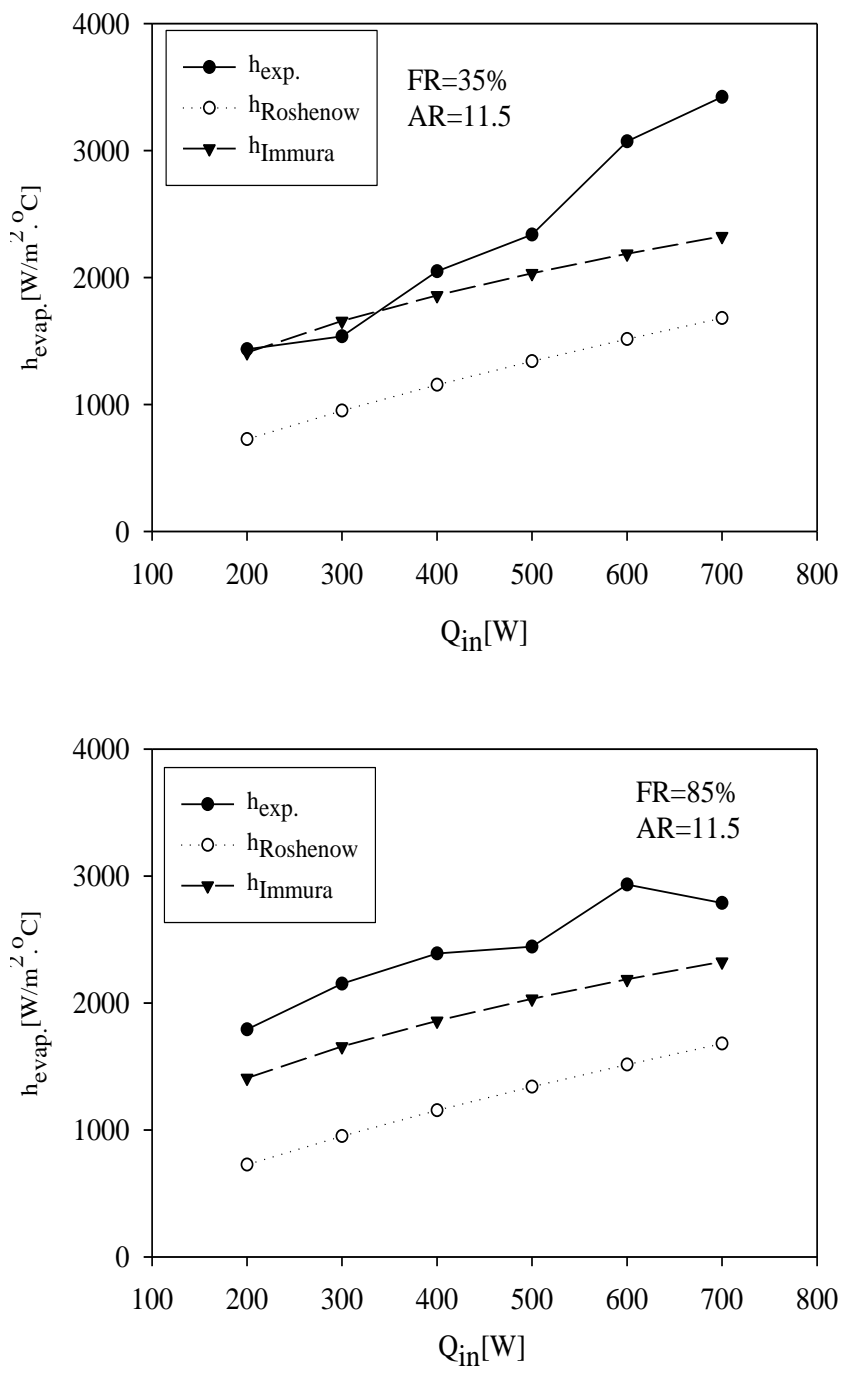

Figure(7):The heat transfer coefficient vs.power input of the present work compared with theoretical and empirical correlations $[1,3]$. showed a good agreement with the correlations reported by Roshenow and Immura by $70 \%$. 


\section{7:References}

1. Roshenow, W.M. "A method of Correlating Heat Transfer Data for Surface Boiling Curves," International Journal of Heat Transfer ASME 84,(1962),pp 969.

2. Shiraishi, M., Kikuchi, K., and Yamanishi, T." Investigation of Heat Transfer Characteristics of a Two-Phase Closed Thermosyphon," Japan(1981).

3. Immura, H., Sasaguchi, K., Kozai, H. and Numata, S. "Critical Heat Flux in Two-Phase Closed Thermosyphon," Int. J. Heat Mass Transfer vol.26 No.8,(1983),pp 1181-1188.

4. Faghri, A., Chen, M.-M., and Morgan, M." Heat Transfer Characteristics in Two-Phase Closed Conventional and Concentric Annular Thermosyphon" Journal of Heat Transfer Vol.111,August(1989),pp.611-618.

5. Peterson, G.P. "An Introduction to Heat Pipes Modeling, Testing and Applications, "New York, (1994).

6. Kreith, F., Boehm, R. F., Raithby, G. D. anHollands, K. G. "Heat and Mass Transfer Handbook, "CRC Press LLC,(2000).

7. Yong joo, P., Hwan Kook Kang, and Chul Ju Kim " Heat Transfer Characteristics of a Two Phase Closed Thermosyphon to the Fill Charge Ratio," Int. J. of Heat and Mass Transfer 45,(2002),pp 4655-4661.

8. Lin, L., Ponnapan, R., and Leland, J." Heat Performance Miniature Heat Pipe," Int. J. of Heat and Mass Transfer 45, (2002),pp 3131-3142.

9. Tahsin Basaran, and Serhan Kucuka" Flow Through a Rectangular Thermosyphon at Specified Wall Temperatures," Int. Comm. Heat Mass Transfer, vol.30, No.7,(2003), pp 1027-1039.

10. Bejan. and Kraus, A.D. "Heat Transfer Handbook," Published by John Wiley\& Sons, Inc., Hoboken , New Jersey,(2003).

11. Noie, S.H." Heat Transfer Characteristics of a Two-Phase Closed Thermosyphon," Journal of Applied Thermal Engineering 25,(2005),pp 495-506.

12. Kempers, R., Ewing, D., and Ching, C. Y." Effect of Number of Mesh Layers and Fluid Loading on the Performance of Screen Mesh Wicked Heat Pipes," Journal of Applied Thermal Engineering 26,(2006),pp 589-595.

13. Carbajal, G., Sobhan, C. B., Peterson, G. P., Queheillat, D.T., and Wadley, H.N.G." Thermal Response of a Flat Heat Pipe Sandwich Structure to a Localized Heat Flux,"49,(2006),pp 4070-4081.

14. Reay, D. A., and Kew, P. "Heat Pipes Theory, Design and Applications," $5^{\text {th }}$ Edition ,Britain,(2006).

15. Jiao, B., Qiu, L. M., Zhang, X. B., and Zhang, y." Investigation on the Effect of Filling Ratio on the Steady-State Heat Transfer Performance of a Vertical Two-Phase Closed Thermosyphon," Journal of Applied Thermal Engineering 28,(2008),pp 1417-1426.

16. Kandekar, S., Joshi, Y.M., and Mehta, B." Thermal Performance of Closed Two-Phase Thermosyphon Using Nanofluids," Int. J. of Thermal Science 47,(2008),pp 659-667. 